\title{
Influence of Cysteine to Cysteic Acid Oxidation on the Collision-Activated Decomposition of Protonated Peptides: Evidence for Intraionic Interactions
}

\author{
Odile Burlet \\ Department of Medicine, Baylor College of Medicine, and Department of Chemistry, University of Houston, \\ Houston, Texas, USA
}

\author{
Chao-Yuh Yang and Simon J. Gaskell \\ Department of Medicine, Baylor College of Medicine, Houston, Texas, USA
}

\begin{abstract}
Oxidation of cysteine residues to cysteic acids in C-terminal arginine-containing peptides (such as those derived by tryptic digestion of proteins) strongly promotes the formation of multiple members of the $Y^{\prime \prime}$ series of fragment ions following low energy collision-activated decomposition (CAD) of the protonated peptides. Removal of the arginine residue abolishes the effect, which is also attenuated by conversion of the arginine to dimethylpyrimidylornithine. The data indicate the importance of an intraionic interaction between the cysteic acid and arginine side-chains. Low energy CAD of peptides which include cysteic acid and histidine residues, also provides evidence for intraionic interactions. It is proposed that these findings are consistent with the general hypothesis that an increased heterogeneity (with respect to location of charge) of the protonated peptide precursor ion population is beneficial to the generation of a high yield of product ions via several charge-directed, low energy fragmentation pathways. Furthermore, these data emphasize the significance of gas-phase conformations of protonated peptides in determining fragmentation pathways. (J Am Soc Mass Spectrom 1992, 3, 337-344)
\end{abstract}

$\mathrm{T}$ The combination of fast atom bombardment (FAB) and tandem mass spectrometry (MS/MS) is increasingly widely accepted as an important technique for the structural analysis of polypeptides [1-5]. The approach is particularly valuable when structural modifications (including $\mathrm{N}$-terminal blocking) render inapplicable classical sequencing techniques based on Edman chemistry. Furthermore, the application of increasingly sophisticated algorithms has established the potential of automated methods of interpretation for rapid mass spectrometry-based sequencing of peptides (see, e.g., refs 6-8). Much of the most prominent work on the use of MS/MS for the elucidation of the structures of peptides of biological (rather than synthetic) origin has involved four-sector instruments. In such analyses decomposition of pro-

Address reprint requests to Simon J. Gaskell, Department of Medicine, Baylor College of Medicine, One Baylor Plaza, Houston, TX 77030 tonated peptides is promoted by high energy (several kiloelectronvolts in the laboratory frame of reference) collisional activation. The principal fragmentation types are now well understood and include cleavages of the peptide backbone with charge retention on the N-terminal fragment (mainly $A$ and $B$ series ions, in the Roepstorff nomenclature [9], or $a$ and $b$ using the Biemann modification [1]) or the C-terminal fragment (mainly the $\mathrm{Y}^{\prime \prime}$ or $\mathrm{y}$ series, according to the nomenclature). In addition, concomitant side-chain cleavage yields both $\mathrm{N}$-terminal (d series [10]) and $\mathrm{C}$-terminal (v [10] and $w$ [11] series) product ions. Many, if not all, of the observed fragmentations may be classified as "charge-site remote" with preferential charge retention on a particular fragment determined by the presence of a basic residue [10]. Thus, for example, an arginine residue at or close to the $\mathrm{C}$-terminus leads to a predominance of $\mathrm{Y}^{\prime \prime}$ ions.

Collision-activated decomposition (CAD) experiments performed on triple quadrupole or hybrid sector/quadrupole instruments typically involve low col- 
lision energies (10-50 eV), multiple collisions with target gas, and extended residence times (tens of microseconds) in the decomposition region. The pioneering work of Hunt and co-workers [2], together with more recent direct comparisons of hybrid and four-sector instruments [12-14] has indicated that the decompositions of protonated peptides can be substantially more complex in the low energy CAD regime compared with the high energy experiment. Thus, for example, "internal" fragments, designated $\left(B_{m} Y_{n}\right)$ ' and $\left(A_{m} Y_{n}\right)^{\prime}$ in the Roepstorff nomenclature [9], are of generally greater relative abundance in low energy CAD spectra.

Recent work from this laboratory has provided additional evidence for the potential complexity of fragmentations arising via low energy processes. $\left[{ }^{18} \mathrm{O}_{2}\right]$-Labeling of the C-terminal carboxyl group revealed a rearrangement process [15] that resulted in the loss of the C-terminal amino acid residue but retention of a C-terminal oxygen. Further study of the same rearrangement provided evidence for additional ${ }^{18} \mathrm{O}$-incorporation into the charge-retaining fragment [16]. These data have suggested, inter alia, the effect of the gas-phase conformation of peptides in determining fragmentation pathways.

The fragmentation of protonated peptides following low energy $\mathrm{CAD}$ remains, however, incompletely understood. Attempts at improved understanding of peptide decompositions under the low energy regime are justified not only by the extensive potential of the relatively widely available triple quadrupole instruments, but also by the increasing interest in MS/MS using ion trapping techniques [17].

A common strategy for protein sequencing using MS/MS includes initial trypsin hydrolysis and partial separation of the resulting peptides. The study of cysteine-containing peptides reported here originated in our study of peptides derived from apoprotein B-100 (apo B-100) following trypsin hydrolysis. Apo B-100 is the major protein component of low density lipoprotein, which is the principal carrier of cholesterol in the blood. Oxidative modification of apo B-100 is known to influence cholesterol accumulation in the cells [18, 19]. The structural changes accompartying lipoprotein oxidation are no doubt complex but may include oxidation of cysteine to cysteic acid residues.

During the course of our study on apo B-100 tryptic fragments, low energy CAD product ion spectra of native cysteine-containing peptides and their oxidized forms were recorded. An apparent promotion of the $Y^{\prime \prime}$-series of ions (corresponding to the cleavage of the peptide bonds with charge retention on the C-terminal fragments) was observed in the spectra of the oxidized forms. Cysteine residues were converted to their cysteic acid analogues with performic acid. Oxidation of proteins using performic acid was first used by Sanger [20] for the scission of disulfide bonds. More recently, the oxidation of protein digests has been used in conjunction with FAB/MS to indicate the presence of disulfide moieties [21]. For these studies, however, no MS/MS data have been reported.

The aim of the work reported here was to study further the effect of oxidation of cysteine residues on the product ion spectra of protonated tryptic peptides. The data are interpreted in terms of hypotheses that are of general significance to the understanding of the low energy CAD of peptides.

\section{Experimental}

\section{Materials}

Synthetic peptides (prepared by using standard procedures) were kindly provided by Drs. J. T. Sparrow and R. Cook. Hydrogen peroxide 30\% (Fisher Scientific Co., Fair Lawn, NJ) and formic acid (J. T. Baker Chemical Co., Phillipsburg, NJ) were used without further purification. Acetylacetone and triethylamine (Fisher) were redistilled under nitrogen prior to use. Carboxypeptidase $P$ and trypsin were purchased from Sigma Chemical Co. (St. Louis, MO) and were used as received.

Oxidation to cysteic acid forms of cysteinyl peptides. Performic acid was prepared by allowing $0.1 \mathrm{~mL}$ of $30 \%$ $\mathrm{H}_{2} \mathrm{O}_{2}$ to react with $1 \mathrm{~mL}$ of formic acid for $1 \mathrm{~h}$ at $25{ }^{\circ} \mathrm{C}$. A one hundredfold molar excess of performic acid was then added to the lyophilized peptides (20 to $200 \mathrm{nmol}$ ) and allowed to react for $30 \mathrm{~min}$ at $0{ }^{\circ} \mathrm{C}$. The reaction was terminated by immersion in liquid nitrogen followed by lyophilization.

Dimethylpyrimidylomithyl derivatives of arginyl peptides. The arginine-containing peptide, Gly-Phe-Leu-CysGly-His-Tyr-Arg, was converted to the dimethylpyrimidylornithine (DMPO) analogue by using the procedure described by Thorne et al. [15]. To 200 nmol of lyophilized peptide were added $50 \mu \mathrm{L}$ of water, $100 \mu \mathrm{L}$ of ethanol, and $50 \mu \mathrm{L}$ of triethylamine. The sample was capped under nitrogen and vortexed. Acetylacetone $(100 \mu \mathrm{L})$ was added to the sample under a stream of nitrogen, and the sample was capped under nitrogen, vortexed, and heated at $100^{\circ} \mathrm{C}$ for 1 h. After evaporation under nitrogen, water $(250 \mu \mathrm{L})$ and glacial acetic acid $(25 \mu \mathrm{L})$ were added to the oily sample and the mixture was again heated at $100^{\circ} \mathrm{C}$ for $12 \mathrm{~min}$. The cool sample was extracted three times with $500 \mu \mathrm{L}$ of diethyl ether, and the aqueous sample was evaporated under a stream of nitrogen. The residual oily material was dissolved in a $50 / 50(\mathrm{v} / \mathrm{v})$ mixture of methanol/water prior to $\mathrm{FAB} / \mathrm{MS} / \mathrm{MS}$ analysis.

Carboxypeptidase $P$ digestion of peptides. Glu-Glu-LeuCys-Thr-Met-Phe-Mle-Arg and Gly-Phe-Leu-Cys-GlyHis-Tyr-Arg (50 and $200 \mathrm{nmol}$ ) were dissolved in 100 $\mu \mathrm{L}$ of $5 \times 10^{-2} \mathrm{M}$ ammonium acetate buffer ( $\mathrm{pH}$ 5.05) and to this was added carboxypeptidase P (CPP) (0.1 
and $1 \mathrm{U}$, where $1 \mathrm{U}$ corresponds to the amount of CPP required to hydrolyze $1 \mu \mathrm{mol}$ of $\mathrm{N}-\mathrm{CBZ}-\mathrm{L}$ glutamyl-L-tyrosine to N-CBZ-glutamate and L-tyrosine per minute at $\mathrm{pH} 3.7$ at $30^{\circ} \mathrm{C}$ ). The digestion was carried out at $23^{\circ} \mathrm{C}$. The course of the reaction was followed by withdrawing $2 \mu \mathrm{L}$ aliquots of the reaction mixture and analyzing them by FAB/MS. The reaction was stopped by acidification with an equal volume of glacial acetic acid.

Trypsin digestion of peptides. Gly-His-Asn-Phe-MetVal-Arg-Asn-Phe-Arg-Cys-Gly-Gln-Pro-Leu-Gln-AsnLys (50 nmol) was digested with bovine pancreatic trypsin, type III, in an enzyme-ta-substrate ratio of $1: 100(w / w)$. The reaction was carried out in $100 \mu \mathrm{L}$ of $5 \times 10^{-2} \mathrm{M}$ ammonium acetate buffer ( $\mathrm{pH} \mathrm{6.8)}$ at 23 ${ }^{\circ} \mathrm{C}$ and was stopped after $2 \mathrm{~h}$ by acidifying with an equal volume of glacial acetic acid.

\section{Mass Spectrometry}

AIl analyses were performed by using a VG ZAB SEQ hybrid mass spectrometer (VG Analytical Ltd., Manchester, UK) with the configuration $\mathrm{BEqQ}(\mathrm{B}=$ magnetic sector, $\mathrm{E}=$ electric sector, $\mathrm{q}=$ radiofrequency-only quadrupole, $Q=$ quadrupole mass filter). Ionization by FAB used xenon atoms with energies of $8 \mathrm{keV}$ as the primary beam. The liquid matrix used was glycerol or a $1 / 1$ mixture of thioglycerol $/ 2,2^{\prime}$-dithiodiethanol saturated with oxalic acid. Low energy $\mathrm{CAD}$ used argon as collision gas at a pressure of 1.6 to $2.7 \times 10^{-4} \mathrm{mbar}$ in the quadrupole collision cell (as estimated from the recorded manifold pressure and the conductance of the system). These conditions represent an attenuation of the transmitted beam of $50 \%$ to $60 \%$. The collision energy was 11-13 $\mathrm{eV}$ in the laboratory frame of reference. Precursor ion resolution was at least unit. The quadrupole mass analyzer was operated at $1-3-u$ resolution. High energy CAD mass-analyzed ion kinetic energy spectrometry (MIKES) analyses used argon as collision gas in the second field-free region to a sufficient pressure to decrease the precursor ion beam intensity by $50 \%$. Product ion spectra were acquired via the VG 11-250 data system in "multichannel analyzer" mode. Scans were of 10-s duration, and 15-20 scans were accumulated. For comparison of data between native and oxidized forms of the same peptide, product ion spectra were acquired with a similar intensity of the precursor ion beam.

\section{Results}

As an initial stage in the development of an analytical strategy to assess the structural changes associated with oxidation of apoprotein B-100 (apo B-100) [22], two synthetic nonapeptides were studied. The structures, Gly-Thr-Tyr-Gly-Leu-Ser-Cys-Gln-Arg
(GTYGLSCQR) and Glu-Glu-Leu-Cys-Thr-Met-PheIle-Arg (EELCTMFIR), corresponded to apo B-100 tryptic fragments representing residues 1472 to 1480 , and 4187 to 4195 , respectively. Figure 1a shows the product ion spectrum of protonated EELCTMFIR, obtained following low energy collisional activation (CA) in the quadrupole collision cell of the hybrid instrument. A series of $Y^{\prime \prime}$ ions and several $Y^{\prime \prime}-17$ ions as well as a series of $B$ ions and several B-18 ions are present but the signal/background ratio is generally low. The $\mathrm{Y}_{1}^{\prime \prime}$ is abundant, reflecting the favored charge retention on the C-terminal arginine residue. Overall, the quality of the spectrum is poor, with regard to both signal/background ratio and clarity of sequence information.

Oxidation of the native nonapeptide with performic acid converted the cysteine residue (R-SH) to the cysteic acid form $\left(\mathrm{R}-\mathrm{SO}_{3} \mathrm{H}\right)$, and the methionine residue ( $\mathrm{R}-\mathrm{S}-\mathrm{CH}_{3}$ ) to the methionine sulfone ( $\mathrm{R}-\mathrm{SO}_{2}$ $\mathrm{CH}_{3}$ ), as illustrated in Scheme $\mathrm{I}$. The product ion spectrum of the oxidized form of EELCTMFIR is presented in Figure 1b. To permit a valid comparison of the product ion spectra before and after oxidation, the two spectra were recorded with similar precursor ion abundances. For the oxidized form (Figure 1b) the complete series of $Y^{\prime \prime}$ ions (except $Y_{B}^{\prime \prime}$ ) is present with a dramatically improved signal/background ratio. $Y_{1}^{\prime \prime}$ no longer predominates. The high fragmentation yield suggested by the appearance of the spectrum of the oxidized form of the peptide was explicitly determined. An approximately fourfold improvement in the fragmentation yield of the oxidized peptide versus native peptide was found. Calculations were based on the integration of product ion currents and comparison of products/precursor abundance ratios for the native and oxidized peptides. Two different approaches using peak heights and peak areas gave similar results.

Equivalent data were obtained for the peptide GTYGLSCQR before and after oxidation of the cys-

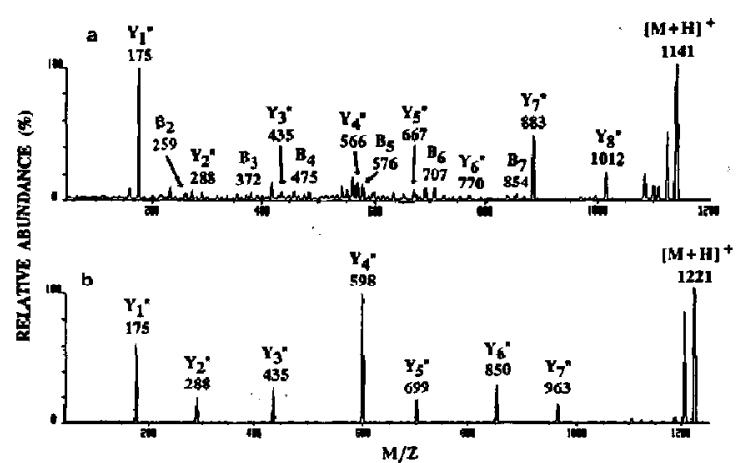

Figure 1. Low energy CAD product ion spectra of the $[M+$ $\mathrm{H}]^{+}$ions of (a) native EELCTMFIR at $m / z$ 1141, and (b) the oxidized form of EELCTMFIR at $m / z$ 1221. $Y^{m}-17$ and B-18 ions present in the spectrum were not labeled for the clarity of the figure. 


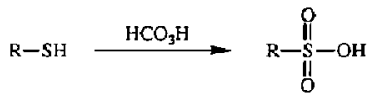

$$
\begin{aligned}
& \text { Sulfonic acid form }
\end{aligned}
$$

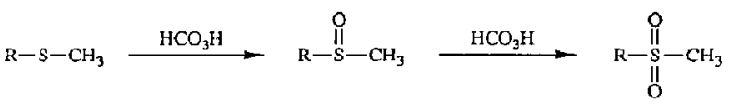

$$
\begin{aligned}
& \text { Sulfoxide form Sulfone form }
\end{aligned}
$$

teine residue to cysteic acid (Figure 2). An equally striking improvement in spectral quality was observed; again, the product ion spectrum of the protonated oxidized peptide was dominated by the $Y^{\prime \prime}$ series of ions.

Thus, a comparison of the product ion spectra obtained for the native and oxidized forms of the two nonapeptides studied shows an enhanced decomposition efficiency after oxidation, with favored formation of the $Y^{\prime \prime}$-series ions.

Truncated peptides derived by C-terminal digestion of EELCTMFIR. The nonapeptide EELCTMFIR was digested with carboxypeptidase $P$ to yield the truncated sequence, EELCTMFI. The latter was then oxidized with performic acid to generate the corresponding cysteic acid form. Product ion spectra of the native EELCTMFI and its oxidized analogue are shown in Figure $3 a$ and $b$, respectively. The major product ions observed for the native peptide (Figure $3 a$ ) correspond to the $B_{6}$ and $B_{7}$ fragments; loss of water from these ions is also observed. Other ions present in lower abundance include $B_{5}$ and the series $Y_{2}^{\prime \prime}$ through $Y_{6}^{\prime \prime}$. For the oxidized analogue (Figure $3 b$ ), the major product ions are $B_{5}, B_{6}$, and $B_{7}$. Minor peaks correspond to the $B_{3}, B_{4}, Y_{3}^{\prime \prime}, Y_{4}^{\prime \prime}$, and $Y_{5}^{\prime \prime}$ ions. Thus, for this truncated peptide, which lacks a C-terminal argi-

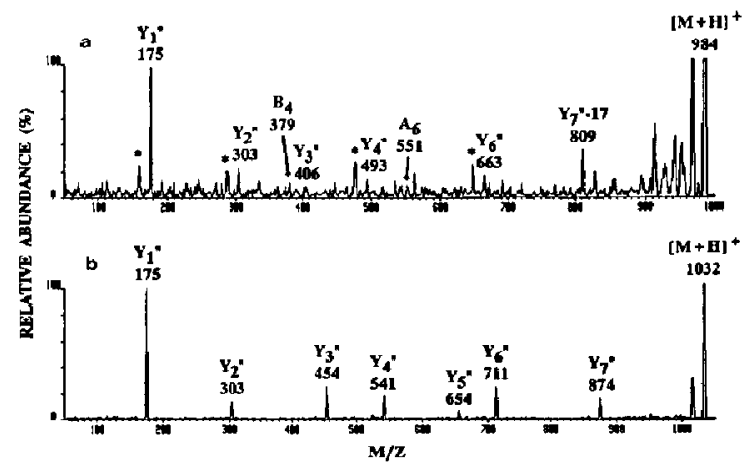

Figure 2. Low energy CAD product ion spectra of the $[M+$ $\mathrm{H}^{+}$ions of (a) native GTYGLSCQR at $m / z$ 984, and (b) the oxidized form of GTYGLSCQR at $m / z$ 1032. Asterisks indicate $17 \mathrm{u}$ losses $\left(\mathrm{NH}_{3}\right)$ from $\mathrm{Y}^{\prime \prime}$ ions.

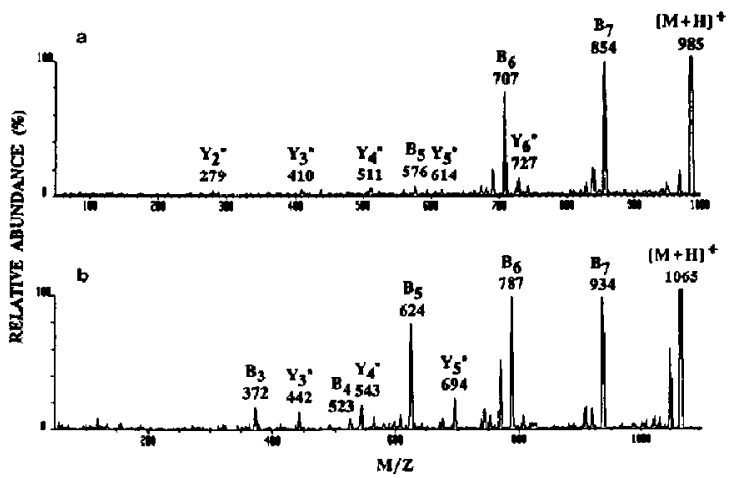

Figure 3. Low energy CAD product ion spectra of the $[M+$ $\mathrm{H}]^{+}$ions of (a) native EELCTMFI at $m / z 985$, and (b) the oxidized form of EELCTMFI at $m / 21065$.

nine residue, the single pronounced difference between the product ion spectra of the native and the oxidized forms is the more prominent $B_{5}$ ion. This fragment represents cleavage between the threonine and the methionine sulfone residues with retention of the charge on the N-terminal fragment.

Further digestion of EELCTMFI with carboxypeptidase $\mathrm{P}$ yiclded two additional peptides, EELCTMF and EELCTM, shortened by one and two amino acid residues, réspectively. Their cysteic acid/methionine sulfone forms were prepared. The product ion spectra obtained for the native peptides (not shown) included the $B_{6}$ ion of EELCTMF and the $B_{4}$ ion of EELCTM as major fragmentations. The product ion spectra of the corresponding oxidized forms displayed the $B_{6}$ and $B_{5}$ ions of EELCTMF, and the $B_{5}$ ion of EELCTM. In both cases the promution of the $B_{5}$ ion was observed. Thus for this series of truncated peptides, which lack a C-terminal arginine residue, the effect of oxidation was only to promote one fragmentation corresponding to cleavage of the peptide bond adjacent to the oxidized methionine residue. Moreover, the decomposition efficiencies apparent from these spectra were very similar for the native peptides and their oxidized analogues.

Ihus, a comparison of the product ion spectra obtained for the protonated nonapeptides (EELCTMFIR and GTYGLSCQR) and their oxidized analogues, together with data for the C-terminal truncated peptides, suggests that the promotion of the $\mathrm{Y}^{\prime \prime}$ series of ions is associated with the combined presence of the C-terminal arginine residue and the sulfonic acid moiety. This is consistent with a specific intraionic interaction between the sulfonic acid and the basic sidechain of the arginine residue, as discussed further, below.

GFLCGHYR and C-terminal truncated analogues. A second series of structural analogues was analyzed to examine further the influence of an arginine residue on the fragmentation of protonated cysteic acid-con- 
taining peptides. The product ion spectrum of the synthetic peptide, Gly-Phe-Leu-Cys-Gly-His-Tyr-Arg (GFLCGHYR), is shown in Figure 4a. The $Y_{1}^{\prime \prime}$ ion is the most abundant product ion, with $Y_{2}^{\prime \prime}$ through $Y_{5}^{\prime \prime}$ ions also detected. A few $\mathrm{N}$-terminal ions are also observed: $B_{6}, A_{6}, B_{7}$, and $A_{7}$. The product ion spectrum of the oxidized form of GFLCGHYR is presented in Figure $4 \mathrm{~b}$. The $Y^{n}$ series of ions (except $Y_{7}^{\prime \prime}$ ) and only one $\mathrm{N}$-terminal ion $\left(B_{7}\right)$ are detected. The overall quality of the product ion spectrum is again improved upon oxidation of the native peptide.

High energy CAD (MIKES) analyses (data not shown) were also performed on the native and oxidized forms of GFLCGHYR. The Y"-series ions were again promoted following oxidation of the peptide to the cysteic acid-containing form. In addition, $w$ ions $\left(w_{5}, w_{6}, w_{7}\right)$ were observed in both spectra, corresponding to concomitant fragmentation of peptide bonds and amino acid side-chains with charge retention on the C-terminal fragment [11]. $w$ ions are frequently observed in high energy, but not low energy, CAD spectra of protonated peptides [13, 14].
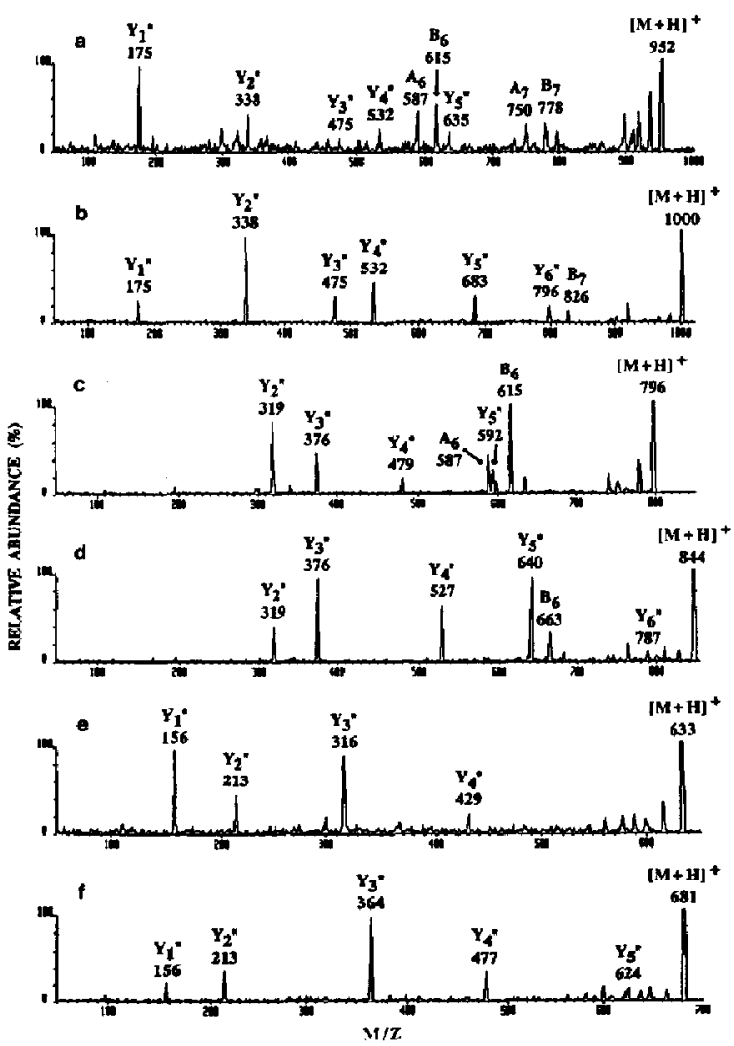

Figure 4. Low energy CAD product ion spectra of the $[\mathrm{M}+$ $\mathrm{H}]^{+}$ions of (a) native GFLCGHYR at $m / z$ 952, (b) the oxidized form of GFLCGHYR at $m / z$ 1000, (c) native GFLCGHY at $m / z$ 796, (d) the oxidized form of GFLCGHY at $m / z$ 844, (e) native GFLCGH at $m / z$ 633, and (f) the oxidized form of GFLCGH at $m / z 681$.
When the oxidized form of GFLCGHYR was analyzed by MIKES without gas in the collision cell, the Y"series ions, but no $w$ ions, were observed.

The octapeptide, GFLCGHYR, was then digested with carboxypeptidase $\mathbf{P}$ to yield the truncated peptides GFLCGHY and GFLCGH. The low energy product ion spectrum of GFLCGHY is shown in Figure 4c. It includes prominent $B_{6}$ and $Y_{2}^{\prime \prime}$ ions, corresponding to the peptide bond cleavages adjacent to the basic histidine residue with retention of the charge on the histidine-containing fragment. Other $Y^{\prime \prime}$ ions $\left(Y_{3}^{\prime \prime}, Y_{4}^{\prime \prime}\right.$, and $Y_{5}^{\prime \prime}$ ) and the $A_{6}$ ion are detected in lower abundance. The product ion spectrum of the oxidized form of GFLCGHY is shown in Figure 4d. The $Y^{\prime \prime}$ series of ions (except $Y_{1}^{\prime \prime}$ ) and the $B_{6}$ ion are displayed. By comparison with the spectrum of the native peptide (Figure 4c) the relative abundances of the $Y_{2}^{\prime \prime}$ and $B_{6}$ ions are decreased and the abundances of the $Y_{3}^{\prime \prime}, Y_{4}^{\prime \prime}$, $Y_{5}^{\prime \prime}$ and $Y_{6}^{\prime \prime}$ ions are increased. The reduction following oxidation in the relative abundances of the two ions resulting from the cleavage of the peptide bond on each side of the histidine residue suggests that the cysteic acid residue influences the properties of the histidine residue with respect to promotion of fragmentation or retention of charge.

The product ion spectrum of protonated GFLCGH is shown in Figure 4e. $Y^{\prime \prime}$-series ions are prominent, with $Y_{1}^{\prime \prime}$ being particularly abundant, as expected from the presence of the histidine residue at the C-terminus. The equivalent spectrum for oxidized GFLCGH (Figure $4 f)$ is also dominated by $Y^{n}$ ions, but $Y_{1}^{*}$ is of markedly reduced relative abundance. Again, the data suggest a modification of the properties of the histidine residue by the presence of the cysteic acid.

Dimethylpyrimidylomithyl analogue of GFLCGHYR. The arginine residue of GFLCGHYR was converted to the dimethylpyrimidylornithyl analogue (the "DMPO derivative") by reaction with acetylacetone, as shown in Scheme II. This derivative blocks the guanidino function of the arginine side chain by forming a pyrimidyl ring, with an expected reduction of the basicity of the residue. The product ion spectrum (not shown) of protonated GFLCGHYR as the DMPO derivative included both $\mathrm{C}$ - and $\mathrm{N}$-terminal fragment

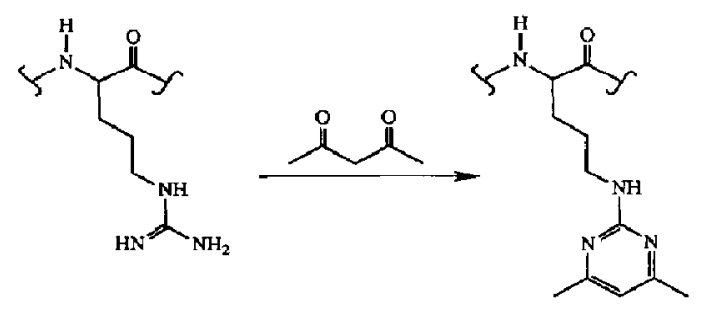

Arginyl residue

DMPO derivative 
ions: $Y_{6}^{\prime \prime}, Y_{5}^{\prime \prime}, Y_{4}^{\prime \prime}, Y_{3}^{\prime \prime}, Y_{2}^{\prime \prime}, B_{7}, B_{6}, A_{7}, A_{6}$. The $B_{7}$ ion was particularly prominent. The equivalent spectrum of the oxidized peptide as the DMPO derivative included the same fragment ions at similar relative abundances. Thus, conversion of the arginine residue to the DMPO analogue apparently blocks interaction with the cysteic residue.

Peptide incorporating a C-terminal lysine. Tryptic digestion of proteins yields fragments characterized by a C-terminal arginine or lysine residue, resulting from the specificity of tryptic cleavage. It was therefore of interest to assess evidence for lysine/cysteic acid intraionic interaction in the gas phase to parallel the apparent arginine/cysteic acid interaction. The product ion spectrum of the synthetic peptide, Cys-GlyGln-Pro-Leu-Gln-Asn-Lys (CGQPLQNK), is shown in Figure 5a. The most abundant ion, of $m / z$ 599, can be attributed to the $Y_{5}^{m}$ or $A_{6}$ fragments, which are isobaric. Methylation of the peptide resulted in a product ion spectrum (not shown) where the peak at $\mathrm{m} / z 599$ was totally shifted to $m / z 613$, suggesting that $m / z$ 599 is due to the $Y_{5}^{\prime \prime}$ ion. Other C-terminal, N-terminal, and "internal" $\left(B_{m} Y_{n}\right)$ ' fragment ions are also observed (see Figure 5a).

The product ion spectrum of the uxidized form of CGQPLQNK is shown in Figure 5b. The major fragment ion is the $Y_{5}^{\prime \prime}$, representing cleavage adjacent to the proline residue. It has previously been noted that a proline residue favors the fragmentation of the peptide bond involving the proline amino group to yield the corresponding $Y^{\prime \prime}$ ion [2]. Other product ions, principally of the $Y^{\prime \prime}$ series, are present at substantially lower abundance. Thus, for the example of this $C$-terminal lysine-containing peptide, oxidation of the cysteine residue results in promotion of $Y^{\prime \prime}$ ions over other fragment types, with a particular enhancement of $Y_{5}^{\prime \prime}$. These observations are consistent with a lysine/cysteic acid interaction which parallels the arginine/cysteic acid interaction which has been studied in greater detail in the present work.

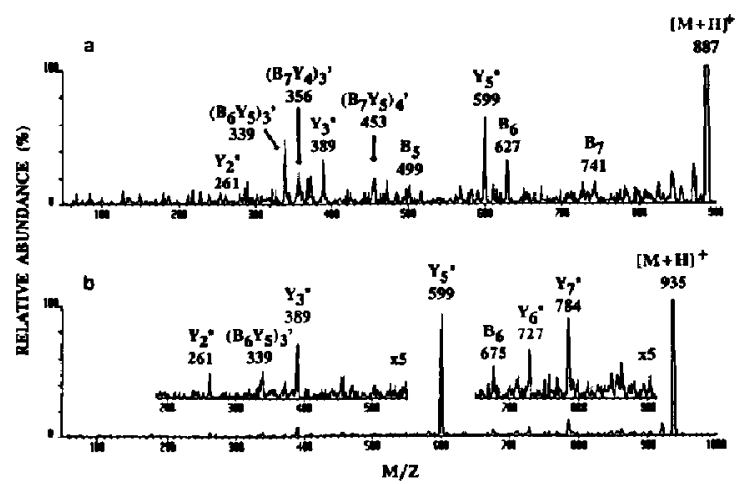

Figure 5. Low energy CAD product ion spectra of the $[M+$ $\mathrm{H}^{+}$ions of (a) native CGQPLQNK at $m / z 887$, and (b) the oxidized form of CGQPLQNK at $m / z 935$.
Methionine-containing peptides. As noted in the study of the synthetic nonapeptide, Glu-Glu-Leu-Cys-ThrMet-Phe-Ile-Arg (EELCTMFIR), oxidation of peptides with performic acid converts methionine residues to the methionine sulfone forms, in addition to the conversion of cysteine residues to their cysteic acid analogues. To assess the separate influence of methionine oxidation on the fragmentation of protonated C-terminal arginine-containing peptides, the synthetic peptide, Gly-His-Asn-Phe-Met-Val-Arg (GHNFMVR), was analyzed before and after oxidation. The product ion spectra (not shown) revealed no significant change in relative abundances of equivalent ions.

\section{Discussion}

This study represents a systematic examination of cysteic acid-containing peptides following initial observation of dramatic differences in the low energy CAD of protonated peptides following oxidation of cysteine residues to cysteic acids. Thus, oxidation results in the strong promotion of Y"'-series ions; both absolute and relative abundances of this fragment type are increased. This effect appears to be dependent on the presence of a C-terminal arginine (or possibly lysine) residue, as typically observed in tryptic fragments of proteins. Conversion of the arginine residue to dimethylpyrimidylornithine attenuates the effect. The data are consistent with a change in fragmentation properties resulting from a specific interaction between the cysteic acid and basic arginine sidechains.

Arginine residues are expected to have a significant influence on the CAD of protonated peptides. Thus, extensive studies of the high energy CAD of protonated peptides $[10,14,23]$ have illustrated that the presence of basic amino acid residues determines the charge-retaining fragment following peptide cleavage. Tryptic peptides containing a C-terminal arginine residue, for example, show a predominance of $Y^{\prime \prime \prime}$ ions over N-terminal fragment ions. Biemann and coworkers [10] have further proposed that fragmentations of peptides containing a strongly basic amino acid residue, such as arginine, should be considered to occur in a "charge-remote" [24] fashion.

Poulter and Taylor [12] have suggested that the presence of a terminal arginine residue is detrimental to the observation of sequence ions following low energy CAD of protonated peptides. This is presumably attributable to the strongly favored association of the proton with the basic arginine side-chain. Removal or modification of the arginine residue may have a marked effect by reducing this propensity for a single site of protonation.

It is postulated that the data described in the present study can be accommodated by a general hypothesis of the beneficial effect of a precursor ion population heterogeneous in charge location. The poor product ion spectra, and the preponderance of $\mathrm{Y}_{1}^{\prime \prime}$ 
over other $\mathrm{Y}^{\prime \prime}$-series ions, observed for cysteine-containing C-terminal arginine peptides are attributed to strongly favored localization of protonation on the arginine side-chain. Oxidation of the cysteine residue generates an acidic site available for interaction with the arginine side-chain, reducing the predominance of protonation on the arginine. The resulting population of $\left[\mathrm{M}+\mathrm{H}^{+}\right.$precursor ions then incorporates multiple sites of protonation, favoring charge-directed peptide bond cleavage via low energy pathways at several sites. $Y^{n}$-type ions are evidently favored over complementary B ions by virtue of the generally Iower energy requirement $[2,25]$.

The general hypothesis proposed here is in keeping with the suggestions of Hunt et al. [2] concerning the charge-directed fragmentation of protonated peptides following low energy CA. These authors postulated that peptide chain folding ("internal solvation") in the gas phase results in the stabilization of multiple sites of charge location, facilitating amide bond cleavage. The present work provides more direct evidence for intraionic interactions.

For the single example (GFLCGHYR) studied here by MIKES incorporating high energy CAD, $Y^{\prime \prime}$-series ions were again promoted by oxidation of cysteine to cysteic acid. The $Y^{\prime \prime}$-series ions were also observed, however, in the MIKES analysis conducted in the absence of collision gas, indicating their origin as metastable decomposition products. Thus, these low energy processes are also favored on the abbreviated time scale of the MIKES experiment. The CAD/MIKE spectrum may be viewed as a superimposition of unimolecular decomposition products and fragments (such as $w$ ions) arising from high energy $C A$. The principal focus of the present work, however, has been the influence of cysteine/cysteic acid oxidation on the low energy CAD spectra of peptide $[\mathrm{M}+\mathrm{H}]^{+}$ ions; more extensive study is required to elucidate fully the implications for high energy CAD analysis.

Analyses in the present study of peptides incorporating cysteine or cysteic acid and basic histidine residues allow further evaluation of the general hypothesis proposed above. Thus, for example, analyses of protonated GFLCGHY, before and after oxidation, indicated that conversion of the cysteine to cysteic acid resulted in reduced prominence of the B- and $Y$ '-type fragments adjacent to the histidine residue (Figure 4). This result is consistent with a lesser tendency for the accommodation of the proton at the histidine residue following interaction of the cysteic acid and histidine side-chains.

In summary, the data reported here indicate specific intraionic interactions between the side-chains of cysteic acid and basic amino acid residues. More generaily, the results are consistent with the notion of the beneficial effect on low energy decomposition spectra of protonated peptides of a population of precursor ions heterogeneous with respect to charge localization. Furthermore, the data provide additional evi- dence for the significance of the gas-phase conformation of ions in determining fragmentation pathways, supplementing evidence obtained from studies of gas-phase rearrangements [15] and isotope exchange [16]. These hypotheses have important implications for the design of appropriate strategies for the analyses of peptides using low energy CAD (such as the utility, or otherwise, of "pre-charged" derivatives [26-28]) and are the subject of continuing study in this laboratory.

\section{Acknowledgments}

The authors are grateful to Drs. J. T. Sparrow and R. Cook (Baylor College of Medicine) who kindly provided the synthetic peptides. This work was supported in part through a generous gift from Glaxo, Inc.

\section{References}

1. Biemann, K. Biomed. Environ. Mass Spectrom. 1988, 16, 99.

2. Hunt, D. F.; Yates, J. R.; Shabanowitz, J.; Winston, 5.; Hauer, C. R. Proc. Natl. Acad. Sci. USA 1986, 83, 6233.

3. Biemann, K. In Biological Mass Spectrometry; Burlingame, A. L.; McCloskey, J. A., Eds.; Elsevier: Amsterdam, 1990; p 170 .

4. Walls, F. C.; Baldwin, M. A.; Falick, A. M.; Gibson, B. W.; Kaur, S.; Maltby, D. A.; Gillece-Castro, B. L.; Medzihradszky, K., F.; Evans, S.; Burlingame, A. L. In Biological Mass Spectrometry; Burlingame, A. L.; McCloskey, J. A., Eds.; Elsevier: Amsterdam, 1990; p 197.

5. Carr, S. A.; Hemling, M. E.; Roberts, G. D. In Macromoieculur Sequencing and Synthesis: Selected Methods and Appications; Schlesinger, D. H., Ed.; Alan R. Liss: New York, 1988; p 83.

6. Sakurai, T.; Matsuo, T.; Matsuda, H.; Katakuse, I. Biomed. Mass Spectrom. 1984, 11, 396

7. Johnson, R. S; Biemann, K. Biomed. Environ. Mass Spectrom. $1989,18,945$.

8. Medzihradszky, K. F.; Hall, S. C.; Maltby, S. C.; Hines, W. M.; Burlingame, A. L. In Techniques in Protein Chemistry II; Villafranca, J., Ed.; Harcourt Brace Jovanovich; San Diego, 1990; p 435.

9. Roepstorf, P.; Fohlman, J. Biomed. Mass Spectrom. 1984, 11, 601.

10. Johnson, R. S.; Martin, S. A.; Bjemann, K. Int. J. Mass Snectrim. Ion Processes 1989, 86, 137

11. Johnson, R. S.; Martin, S. A.; Biemann, K.; Stults, J. T.; Watson, J. T. Anal. Chem. 1987, 59, 2621.

12. Poulter, L.; Taylor, L. Int. J. Mass Spectrom. Ion Processes 1989, 91, 183.

13. Alexander, A. J.; Thibault, P.; Boyd, R. K.; Curtis, J. M; Rinehart, K. L. Int. J. Mass Spectrom. Ion Processes 1990, 98, 107.

14. Bean, M. F.; Carr, S. A.; Thorne, G. C.; Reilly, M. H.; Gaskell, S. J. Anal. Chem. 1991, 63, 1473.

15. Thorne, G. C.; Ballard, K. D.; Gaskell, S. J. I. Am. Soc. Mass Spectrom. 1990, 1, 249.

16. Ballard, K. D.; Gaskell, S. J. J. Am. Chem. Soc., 1992, 114, 64.

17. Glish, G. L.; McLuckey, S. A.; Van Berkel, G. J. Proceedings of the 38th ASMS Conference on Mass Spectrometry and Allied Topics; Tucson, AZ, June 3-8, 1990; p 922.

18. Steinberg, D. Atherosclerosis Rev. 1988, 18, 1. 
19. Brown, M. S.; Goldstein, J. L. Ann. Rez. Biochem. 1983, 52 , 223.

20. Sanger, F. Biochem. /. 1949, 44, 126.

21. Sun, Y.; Smith, D. L. Anal. Biochem. 1988, 172, 130.

22. Yang, C.-Y.; Kim, T. W.; Sparrow, J. T.; Gaskell, S. J. J. Frolein Chem. 1990, 9, 323.

23. Biemann, K. In Methods in Enztymology, Vol. 193; Mc Closkey, J. A., Ed.; Academic: San Diego, 1990; p 455.

24. Jensen, N. J.; Tomer, K. B.; Gross, M. L. J. Am. Chem. Soc. $1985,107,1863$.
25. Alexander, A. J.; Boyd, R. K. Int, I, Mass Spectrom. Ion Processes 1989, 90, 211.

26. Vath, J. E.; Biemann, K. Int. J. Mass Spectrom. Ion Processes $1990,100,287$.

27. Wagner, D. S.; Salari, A.; Gage, D. A.; Leykam, J.; Fetter, J.; Hollingsworth, R.; Watson, J. T. Biol. Mass Spectrom. 1991, 20, 419.

28. Stults, J. T.; Halualani, R.; Wetzel, R. Proceedings of the 37th ASMS Conference on Mass Spectrometry and Allied Topics; Miami Beach, FL, May 21-26, 1989; p 856. 